\title{
Competing controls on groundwater oxygen concentrations revealed in multidecadal time series from riverbank filtration sites
}

\author{
Simon Figura, ${ }^{1,2}$ David M. Livingstone, ${ }^{1}$ and Rolf Kipfer ${ }^{1,2,3}$ \\ Received 27 February 2013; revised 27 September 2013; accepted 1 October 2013; published 18 November 2013.
}

[1] Dissolved oxygen (DO) is an important indicator of groundwater quality, but long time series of groundwater DO concentration are rare. Here we describe and analyze multidecadal time series of groundwater DO data from five Swiss aquifers that are recharged by riverbank filtration $(\mathrm{RBF})$, and relate temporal features of the DO time series to potential forcing factors. Features found in the DO time series include long-term decreases and abrupt increases. Some features occur simultaneously in hydrologically unconnected aquifers, suggesting that external forcing partially determines DO concentrations at RBF sites. The data indicate that: (i) the DO concentration in the losing river is not a critical determinant of groundwater DO concentration; (ii) increasing riverwater and groundwater temperatures, by affecting both the physical solubility of oxygen and DO consumption in the hyporheic zone, probably cause the long-term decline in DO concentration observed in most aquifers investigated; and (iii) a complex interaction between hydrological factors such as groundwater pumping rate and river discharge results in abrupt changes in groundwater DO concentration. Climate models predict higher temperatures and more frequent flood events in central Europe, implying that groundwater DO concentrations at many RBF sites will continue to decrease in the long term, but that irregular high-discharge events, by scouring and unclogging riverbeds, will probably prevent the occurrence of long periods of hypoxia. Nonetheless, the risk of short periods of hypoxia at RBF sites is likely to increase.

Citation: Figura, S., D. M. Livingstone, and R. Kipfer (2013), Competing controls on groundwater oxygen concentrations revealed in multidecadal time series from riverbank filtration sites, Water Resour. Res., 49, 7411 7426, doi:10.1002/2013WR013750.

\section{Introduction}

[2] Riverbank filtration (RBF) is of great importance for the production of drinking water, particularly in Europe [Ray et al., 2002]. One crucial factor affecting groundwater quality and pumping-well management at RBF sites is the concentration of dissolved oxygen (DO). With regard to groundwater quality, a decrease in DO concentration is likely to lower the rates of microbial degradation of contaminants [Chapelle, 1993; Sprenger et al., 2011]. The reduction and dissolution of iron and manganese oxides under anaerobic conditions [von Gunten et al., 1991; Bourg and Bertin, 1993; Hoehn and Scholtis, 2011; Sprenger et al., 2011], and the subsequent formation of precipitates

\footnotetext{
${ }^{1}$ Eawag, Swiss Federal Institute of Aquatic Science and Technology, Dubendorf, Switzerland.

${ }^{2}$ ETH Zurich, Institute of Biogeochemistry and Pollutant Dynamics, Zurich, Switzerland.

${ }^{3}$ ETH Zurich, Institute of Geochemistry and Petrology, Zurich, Switzerland.

Corresponding author: S. Figura, Swiss Federal Institute of Aquatic Science and Technology, Ueberlandstrasse 133, CH-8600 Dubendorf, Switzerland. (simon.figura@eawag.ch)

C2013. American Geophysical Union. All Rights Reserved. 0043-1397/13/10.1002/2013WR013750
}

in the pumping wells as a result of reaeration, are of relevance for the maintenance of pumping wells [Hunt et al., 2002].

[3] The major oxygen input into groundwater at $\mathrm{RBF}$ sites results from the advective transport of DO in the infiltrating river water, although in some cases the input of atmospheric oxygen through the unsaturated zone can also be important [Malard and Hervant, 1999]. On the other hand, oxygen is consumed by microbial respiration in the aquifer and in the hyporheic zone (the transition zone between river and groundwater) [Chapelle, 1993; Malard and Hervant, 1999]. In RBF systems in which the residence time of groundwater in the aquifer is short, most of the oxygen consumption takes place in the hyporheic zone [Beyerle et al., 1999; Malard and Hervant, 1999] and is controlled by the residence time of the water in the hyporheic zone and by the respiration rates of the microbial community located there [Brunke and Gonser, 1997; Malard and Hervant, 1999]. These two factors are themselves affected by a variety of factors. The residence time of water in the hyporheic zone is governed by the hydraulic conductivity of the riverbed, the stream velocity, and the hydraulic head between river and groundwater [Brunke and Gonser, 1997; Boulton et al., 1998]. Respiration rates within the microbial community of the hyporheic zone are affected by the water temperature and by the availability and composition of organic material [Chapelle, 1993; 


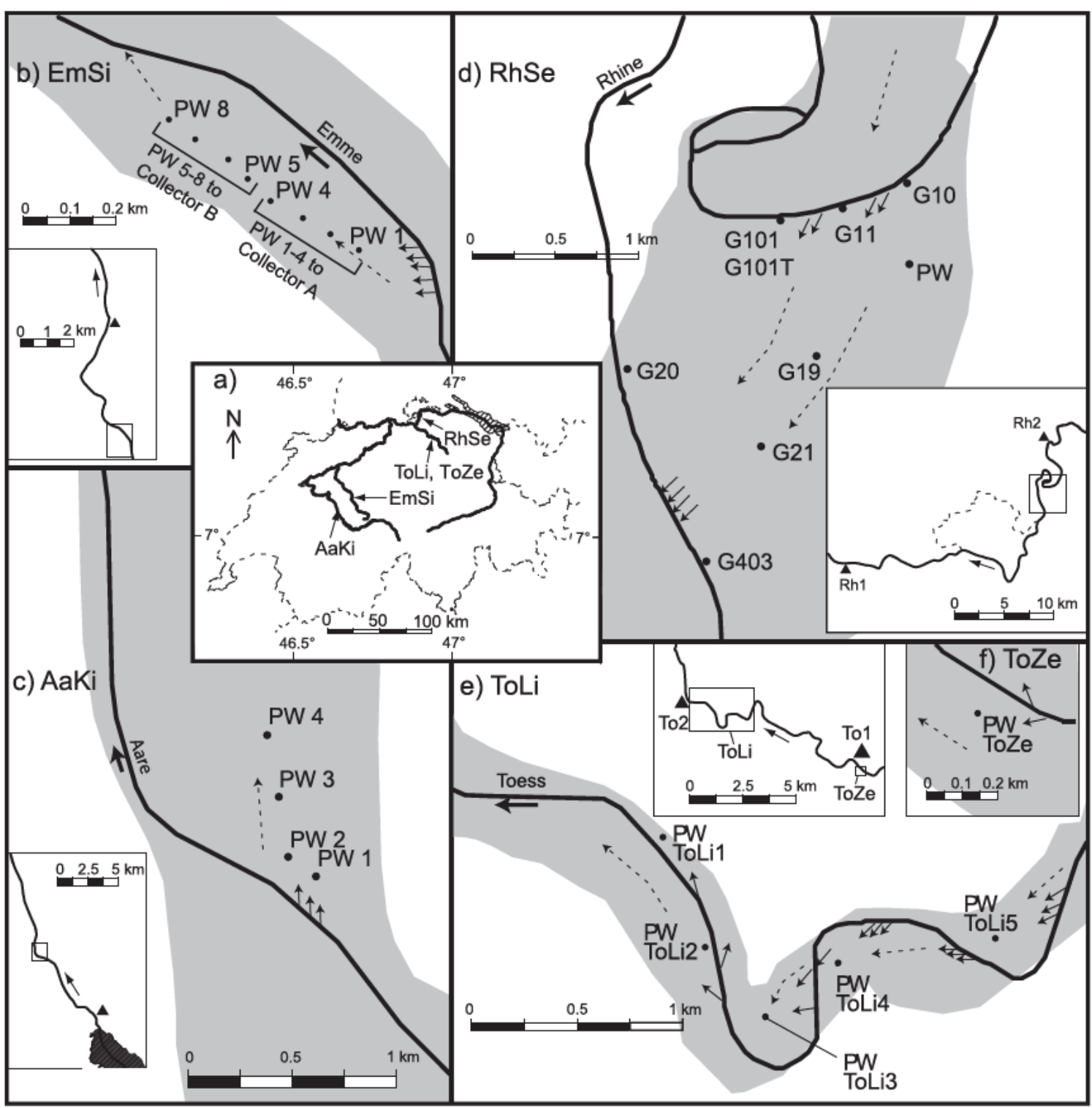

Figure 1. Maps showing the locations of the aquifers and pumping wells. (a) Map of Switzerland showing the locations of the aquifers analyzed in this study and their losing rivers. (b-f) Approximate extent of each of the aquifers (shaded areas); locations of pumping wells and piezometers (points); infiltration and exfiltration sites (solid arrows); and estimated groundwater flow direction (dashed arrows). The insets in Figures $1 \mathrm{~b}-1 \mathrm{e}$ show the locations of the river gauging stations (triangles) with respect to the aquifers.

Brunke and Gonser, 1997; Malard and Hervant, 1999; Sprenger et al., 2011].

[4] Climate change is likely to lead to an increase in groundwater temperature [Kundzewicz et al., 2007; Figura et al., 2011] and to changes in hydrological conditions [Green et al., 2011], and will thus potentially affect oxygen consumption in the hyporheic zone and DO concentrations in groundwater. In 2003, central Europe experienced an extremely hot, dry summer. Regional climate model simulations suggest that by the end of the current century, about every second summer in central Europe could be as warm or warmer, and as dry or dryer, than that of 2003 [Schär et al., 2004]. During the summer of 2003, anaerobic conditions were observed at study sites in Germany [Rohns et al., 2006] and Switzerland [Hoehn and Scholtis, 2011]. At the Swiss study site, the dissolution of iron and manganese in the groundwater [Hoehn and Scholtis, 2011] was followed by the formation of precipitates in the pumping wells (A. Scholtis, unpublished data, 2003), suggesting that future increases in groundwater temperature may have undesirable effects on groundwater pumping well infrastructure.

[5] In view of the above, it is apparent that an analysis of long time series of historical groundwater DO data would be useful to reveal any temporal features (e.g., long-term trends, short-term changes, or fluctuations) that might be related to external driving factors. Such data are rare. However, an extensive search revealed the existence of relevant 
Table 1. Characteristics of Aquifers Investigated ${ }^{\mathrm{a}}$

\begin{tabular}{|c|c|c|c|c|c|}
\hline Name & Elevation (m a.s.1.) & Losing River & Hydraulic Conductivity $^{\mathrm{b}}$ (m s $^{1}$ ) & Depth of Water Table (m) & Thickness of Aquifer (m) \\
\hline EmSi & 685693 & Emme & $24 \times 10^{3}$ & 24 & 1520 \\
\hline$A a K i$ & 539545 & Aare & $2.54 .3 \times 10^{3}$ & 45 & 1520 \\
\hline RhSe & 374385 & Rhine & $15 \times 10^{3}$ & 1020 & 1015 \\
\hline ToLi & 456475 & Toess & $115 \times 10^{3}$ & 2.54 & 1020 \\
\hline ToZe & 520524 & Toess & $18 \times 10^{3}$ & 25 & 3545 \\
\hline
\end{tabular}

${ }^{a}$ Descriptive characteristics of each aquifer investigated, including the elevation of the pumping stations, name of the losing river, hydraulic conductivity, depth of the groundwater table, and thickness of the aquifer. The locations of the aquifers and pumping stations are shown in Figure 1.

${ }^{\mathrm{b}}$ Hydraulic conductivity values for EmSi are from Blau and Muchenberger [1997], and for RhSe, ToLi and ToZe from Kempf et al. [1986]. For Aaki, individual hydraulic conductivities were $3.2 \times 10^{3}, 2.5 \times 10^{3}, 4.3 \times 10^{3}$, and $4.2 \times 10^{3} \mathrm{~m} \mathrm{~s}{ }^{1}$ measured at pumping wells PW1 to PW4, respectively [Kellerhals et al., 1981]. For EmSi, RhSe, and ToZe the hydraulic conductivity was determined at many different points within the aquifer; for $A a K i$ and $T o L i$ it was determined only from pumping tests at each pumping well.

data from several RBF sites in Switzerland. These multidecadal data were collected and collated, and the time series of these data are here described statistically. To identify the processes affecting the long-term behavior of the groundwater DO concentrations, simultaneous time series of groundwater temperature, groundwater level, groundwater pumping rate, river-water DO concentration, river-water temperature, and river discharge rate were also analyzed. The available long-term data allowed us to investigate three possible factors that might control groundwater DO concentrations in the aquifers analyzed: (i) DO concentrations in the losing river; (ii) river-water and groundwater temperatures, which affect the physical solubility of oxygen and microbial respiration in the hyporheic zone, and which have undergone a strong parallel warming in the past [Hari et al., 2006; Figura et al., 2011]; and (iii) changes in hydrological factors, such as groundwater pumping rate, river discharge rate or groundwater level, which might affect the residence time of the water in the hyporheic zone.

[6] To our knowledge, this is the first time that time series of groundwater DO concentration of this length and temporal resolution have been published and statistically described.

\section{Data and Methods}

\subsection{Data}

[7] The data presented in this study resulted from a search for long time series of groundwater data (at least 25 yr) with good temporal resolution (at least four measurements per year) from aquifers in Switzerland that had been affected as little as possible by direct anthropogenic intervention. All time series presented here fulfill these criteria. The data originated from the drinking-water pumping wells of five granular, unconsolidated aquifers on the Swiss Plateau that are recharged predominantly by RBF from four rivers (Figure 1a and Table1). The aquifers are abbreviated here as EmSi, AaKi, RhSe, ToLi, and ToZe, where the first two letters designate the river feeding the aquifer: the Emme $(E m)$, Aare $(A a)$, Rhine $(R h)$, or Toess $(T o)$. Time series of groundwater DO concentration in these aquifers covered periods ranging from 29 to $41 \mathrm{yr}$ (Table 2). Data on groundwater temperature and groundwater level were available from the same aquifers with comparable duration and resolution. Data on pumping rates were available for four of the five aquifers, but mostly for periods of substantially shorter duration (Table 2).
[8] Groundwater temperature and DO concentration were measured directly at the outlets of the pumping wells according to the methods outlined in the Swiss Foodstuffs Handbook [Federal Office of Public Health, 2003]. Groundwater temperature was measured with a precision of $\pm 0.1^{\circ} \mathrm{C}$ and $\mathrm{DO}$ concentration was determined using the Winkler method with a precision of $\pm 0.1 \mathrm{mg} \mathrm{O}_{2} \mathrm{l}^{1}$. If not stated otherwise, groundwater levels were measured in piezometers in the immediate proximity of the pumping wells with an estimated precision of $\pm 0.05 \mathrm{~m}$. Although the operators of some of the pumping wells have installed automatic loggers in the last few years, parallel measurements were continued using the methods described above.

[9] From the rivers, the available data on DO concentration, water temperature, and discharge rate covered periods ranging from 20 to $46 \mathrm{yr}$ with a resolution of at least 12 measurements per year (Table 2). The river gauging stations that supplied the data are operated by Swiss cantonal or federal authorities. The stations are equipped with automatic samplers that take mixed samples over a cross section of the river. Unless stated otherwise, DO concentrations in the rivers were determined weekly or monthly, while river-water temperature and discharge were available as daily means. Because the river gauging stations did not always lie in close proximity to the aquifer infiltration sites, the river-water data might not exactly represent the conditions prevailing at the infiltration sites. However, a comparative analysis of DO data from several gauging stations on the four rivers showed that stations less than $\sim 30 \mathrm{~km}$ apart were broadly similar with respect both to the DO concentrations measured and to the long-term behavior of the DO time series.

\subsubsection{EmSi}

[10] The EmSi aquifer is recharged by the River Emme [Blau and Muchenberger, 1997]. Groundwater has been abstracted from the EmSi aquifer since the 1920s. Neither the river, the pumping well, nor the surroundings of the pumping well have been subject to changes in water management or infrastructure. Groundwater is pumped out of the aquifer at eight wells (PW1-PW8, Figure 1b). Measurements of groundwater temperature and DO concentration were made at the outlets of two collectors (A and B), each of which collects water from four of the eight pumping wells (Figure 1b). Groundwater levels were determined in PW1 (representing Collector A) and PW6 (representing Collector B). Pumping-rate data from Collector A were 
FIGURA ET AL.: COMPETING CONTROLS ON GROUNDWATER OXYGEN CONCENTRATIONS

Table 2. Available Data ${ }^{a}$

\begin{tabular}{lcccc}
\hline \hline \multicolumn{5}{c}{ (i) Groundwater Data } \\
\hline EmSi & DO Concentration & Temperature & Groundwater Level & Pumping Rate \\
Collector A $^{\mathrm{b}}$ & $19792007(\mathrm{Qs}, \mathrm{Ms})$ & $19792007(\mathrm{Qs}, \mathrm{Ms})$ & $19922007(\mathrm{Qs}, \mathrm{Ms})$ & $19782007(\mathrm{Ms})$ \\
$\begin{array}{l}\text { AaKi } \\
\text { PW4 }\end{array}$ & $19972007(\mathrm{Ms})$ & $19972007(\mathrm{Ms})$ & $19972007(\mathrm{Ms})$ & \\
PW1 & $19682005(\mathrm{Qs}, \mathrm{Ms})$ & $19682005(\mathrm{Qs}, \mathrm{Ms})$ & $19682005(\mathrm{Ms})$ & $19972005(\mathrm{Ms})$ \\
RhSe & $19972009(\mathrm{Ms})$ & $19972009(\mathrm{Ms})$ & $19972009(\mathrm{Ms})$ & \\
PW & $19702007(\mathrm{Ms})$ & $19702007(\mathrm{Ms})$ & $19702007(\mathrm{Ms})$ & $19932010(\mathrm{Msum})$ \\
Piezometers & $19701994(\mathrm{Ms})$, & $19701994(\mathrm{Ms})$, & $19701994(\mathrm{Ms})$, & \\
ToLi & $19952006(\mathrm{Am})$ & $19952006(\mathrm{Am})$ & $19952006(\mathrm{Am})$ & \\
ToZe & $19712011(\mathrm{Qs})$ & $19712011(\mathrm{Qs})$ & $19712011(\mathrm{Ms})$ & $20002012($ Asum) \\
\hline
\end{tabular}

(ii) River Data

\begin{tabular}{lccl}
\hline & DO Concentration & Temperature & Discharge rate \\
\hline River Emme & $19832010(\mathrm{Ms})$ & $19762010(\mathrm{Dm})$ & $19762010(\mathrm{Dm})$ \\
River Aare & $19662011(\mathrm{Ms})$ & $19622007(\mathrm{Dm})$ & $19702010(\mathrm{Dm})$ \\
River Rhine Rh1 & $19702010(\mathrm{BWs})$ & $19702010(\mathrm{BWs})$ & $19702010(\mathrm{Dm})$ \\
River Rhine Rh2 & $19922011(\mathrm{Ws})$ & $19842011(\mathrm{Dm})$ & $19702011(\mathrm{Dm})$ \\
$\begin{array}{l}\text { River Toess To1 } \\
\text { River Toess To2 }\end{array}$ & & & \\
\hline \hline
\end{tabular}

${ }^{a}$ Overview of data measured (i) in groundwater and (ii) in the respective losing river. The upper-case letters in parentheses specify the temporal resolution: daily (D), weekly (W), biweekly (BW), monthly (M), quarterly (Q), or annual (A). The lower-case letters in parentheses indicate whether individual spot measurements (s), the mean of several measurements (m), or sums of measurements (sum) were available. (For example, Ms stands for one measured spot value per month and Dm for daily mean values.)

${ }^{\mathrm{b}}$ Data from Collector A were used for the long-term analysis.

${ }^{\mathrm{c}}$ Data from PW4 were used for the long-term analysis.

${ }^{\mathrm{d}}$ From piezometer G101 only data from 19701983 were available.

available at a resolution of one record per month. The data from Collector A comprised two independent sets of measurements covering the periods 1979-2000 and 1997-2007. Annual mean values of DO concentration, temperature, and groundwater level for the two data sets during the overlapping period 1997-2000 differed by less than the respective measurement errors, allowing the two data sets to be combined to cover the 29 yr period 1979-2007. Data from Collector B were available only for the period 1997-2007 (Table 2). The overall similarity of the DO concentrations measured at Collectors A and B (Figure 2a) indicates that the DO concentration measured at Collector A can be assumed to be representative of the whole aquifer. Data from the River Emme were available from a river gauging station $6 \mathrm{~km}$ downstream of the site (Figure 1b, inset and Table 2).

\subsubsection{AaKi}

[11] The $A a K i$ aquifer is approximately $1.5 \mathrm{~km}$ wide and is recharged mainly by the River Aare [Kellerhals et al., 1981]. Since construction of the AaKi pumping wells between 1947 and 1950, there have been no changes in river-water or groundwater management. Groundwater abstraction occurs at four pumping wells (PW1-PW4; Figure 1c), but long-term measurements (1968-2000) were available from only one of these (PW4; Table 2). Groundwater DO concentration and temperature were measured at the outlets of the pumping wells, while groundwater level was determined in a piezometer located approximately 10 $\mathrm{m}$ from PW4. Monthly pumping-rate data from PW4 were available for the period 1997-2005. An additional data set comprising monthly measurements of DO concentration, temperature, and groundwater level was available for 1997-2009 at PW1, PW2, and PW3, and for 1997-2005 at PW4. At PW4, the annual mean values of the two data sets measured during the overlapping period 1997-2000 differed by less than the respective measurement errors for all variables. As in the case of EmSi, this allowed the two data sets to be combined, yielding time series that covered the 38 yr period 1968-2005. The overall similarity of the DO concentrations measured at pumping wells PW1, PW2, PW3, and PW4 from 1997 to 2005 (Figure 3a) indicates that the DO concentration measured at PW4 can be assumed to be representative of the whole aquifer. Data from the River Aare were obtained from a gauging station $9 \mathrm{~km}$ upstream of the site (Figure 1c, inset and Table 2).

\subsubsection{RhSe}

[12] Monitoring of the $R h S e$ aquifer was started in the 1950 s because of the construction of a hydroelectric power plant that led to the impoundment of the River Rhine in the infiltration area. The RhSe aquifer is recharged mainly by the infiltration of river water [Kempf et al., 1986] along the riverbank between piezometers G10 and G101 (Figure 1d). A small proportion of the groundwater infiltrates into the aquifer from the river $2 \mathrm{~km}$ upstream of this site [Kempf et al., 1986]. The pumping well (PW) in the RhSe aquifer was built in 1957. Neither the stretch of river between Lake Constance and the RhSe aquifer nor the surroundings of the $R h S e$ aquifer have been subject to anthropogenic interventions that might have affected the groundwater of the $R h S e$ aquifer.

[13] Groundwater data were available from the pumping well (PW) and eight piezometers (G10, G11, G19, G20, 
G21, G101, G101T, and G403; Figure 1d and Table 2). Note that piezometers G101 and G101T were set in the same location but sampled water from different depths (G101, 1-4 m; G101T, 15-20 m). Monthly pumping-rate data were available for the period 1993-2010. Data from the River Rhine at biweekly resolution or better were obtained from two river gauging stations, one $(R h l)$ approximately $30 \mathrm{~km}$ downstream of the site and one $(R h 2)$ $3 \mathrm{~km}$ upstream of the site (Figure 1d, inset).

\subsubsection{ToLi and ToZe}

[14] The ToLi and ToZe aquifers (Figures 1e and 1f) are part of the $45 \mathrm{~km}$ long Toess Valley aquifer, which is recharged by infiltration from the River Toess [Kempf et al., 1986]. Groundwater flow in the area between ToLi3 and ToLi4 was extensively studied by Beyerle et al. [1999] and Mattle et al. [2001]. The pumping wells in both aquifers were built in the 1960s. The River Toess has not been subject to any changes in water management upstream of pumping well ToLi2. However, $200 \mathrm{~m}$ of the river between ToLi1 and ToLi2 was revitalized in 2001. For the revitalization, linings on the riverbank were removed and an artificial gravel island was built in the middle of the river, leading to erosion of the riverbank and enlargement of the river and the riparian zone from $\sim 20$ to $\sim 50 \mathrm{~m}$.

[15] Groundwater data were available from five pumping wells in the ToLi aquifer (ToLi1-ToLi5) and one pumping well in the ToZe aquifer (Table 2). Pumping rate data available from the five pumping wells in the ToLi aquifer consisted of annual sums of pumped groundwater. Data from the River Toess at weekly resolution or better were obtained at two stations, one (Tol) approximately $6 \mathrm{~km}$ upstream of the ToLi site and $0.5 \mathrm{~km}$ downstream of the ToZe site, and one (To2) $1 \mathrm{~km}$ downstream of the ToLi site and $10 \mathrm{~km}$ downstream of the ToZe site (Figure 1e, inset and Table 2).

\subsection{Methods}

[16] The data were checked for outliers by visual inspection. If a value was suspected to be an outlier, the mean and standard deviation of the data within a $5 \mathrm{yr}$ window centered on the suspect value were calculated. If the difference between the suspect value and the calculated 5 yr mean exceeded three standard deviations, the value was identified as an outlier and deleted (over all data sets, a total of seven outliers were deleted). Data sampling intervals were generally irregular and inconsistent, necessitating standardization. This was accomplished by first interpolating the data at consistent daily intervals using a cubic spline (except over gaps longer than 3 months), then aggregating the interpolated data to yield estimates of monthly and annual means. Interpolation over gaps of 3-6 months was accomplished by fitting a cubic regression model to the monthly mean data. The deviations of the measured data from the cubic regression model were averaged for each month and added to the modeled value to obtain a monthly time series, which was then used to fill the gaps. No interpolation was performed over gaps longer than 6 months. Because the pumping-rate data from the ToLi aquifer consisted of annual sums only, the pumping rates of the EmSi, $A a K i$, and $R h S e$ aquifers were also aggregated to annual sums. This was accomplished at EmSi and AaKi by summing the inter- polated daily mean pumping rates, and at $R h S e$ by summing the monthly sums of the pumping rates.

[17] The data were described and analyzed using standard statistical methods. Temporal trends in the data were assessed using the nonparametric Theil-Sen method [Theil, 1950; Sen, 1968] and tested for statistical significance at the $p<0.05$ level using the nonparametric Kendall $\tau$ statistic [Helsel and Hirsch, 1992]. Spearman rank correlation coefficients for lags of $0-2$ yr were calculated between the time series of annual means of groundwater DO concentration and time series of the annual means of potential driving variables after first removing the trends in the time series, which were determined using the seasonal-trend decomposition procedure of Cleveland et al. [1990] as implemented in function stl of the statistical software $\mathrm{R}$ [ $R$ Development Core Team, 2011]. For each time series, the amplitude of the seasonal variation was estimated by fitting a trigonometric regression model to the monthly mean data. Oxygen saturation concentrations were calculated from the water temperature data and the elevation of the measurement site using the empirical relationship given by Bührer [1975]:

$$
\begin{gathered}
S_{h}=10^{\log (760)-h / 18,400}(14.60307 \quad 0.4021469 T \\
\left.+0.00768703 T^{2} \quad 0.0000692575 T^{3}\right)
\end{gathered}
$$

where $h$ is the elevation of the measuring site in m a.s.1., $T$ is the water temperature in ${ }^{\circ} \mathrm{C}$, and $S_{h}$ is the oxygen saturation concentration in $\mathrm{mg} \mathrm{O}_{2} \mathrm{l}^{1}$ at elevation $h$.

[18] We also conducted an event-based comparison of the time series to investigate the possible nonlinear forcing of groundwater DO concentration by extreme river discharge rates. After checking subjectively whether the occurrence of extreme river discharge rates (either annual or daily) was followed by the occurrence of abrupt, strong changes in groundwater DO concentration, intervention analysis was employed to obtain objective confirmation of any potential relationship found. Intervention analysis is an extension of the autoregressive integrated moving average (ARIMA) time series model to describe the impact of an event on the time series at a specific point in time [Box and Tiao, 1975; Cryer and Chan, 2008]. For the purposes of this analysis, the five highest values of river discharge rate were defined as extreme events. Binary intervention time series were constructed, in which an intervention was defined to take place in the year in which such an extreme river discharge event was observed. One to five interventions were allowed to take place in the intervention time series, which resulted in 31 binary intervention time series (five intervention time series containing only one intervention, 10 containing two interventions, 10 containing three interventions, five containing four interventions, and one containing all five interventions). In a next step, 31 intervention models were constructed as follows (using the notation of Cryer and Chan [2008]):

$$
Y_{t}=N_{t}+m_{t}
$$

where $Y_{t}$ is the modeled groundwater DO concentration, $N_{t}$ is an ARIMA model for groundwater DO concentration that is determined before the intervention model is 
calibrated, and $m_{t}$ is a pulse function that represents the change in the mean caused by the intervention (with $m_{t}=0$ before the intervention takes place). Under the assumption that the impact of an extreme river discharge event on groundwater DO concentration dies out gradually, we used a first-order autoregressive model to represent $m_{t}$, as recommended by Cryer and Chan [2008], which results in $m_{t}$ taking on the form of an exponentially decaying pulse function. The best ARIMA representation of $N_{t}$ was determined by fitting all possible ARIMA models up to an order of (2, $1,2)$. The model with the lowest value of the Akaike information criterion [Akaike, 1974] was the one selected. The model that fitted the DO concentration data best was determined by comparing the root mean square deviations (RMSD) associated with each of the 31 intervention models. The interventions (i.e., the extreme river discharge events) identified by this model were assumed to be responsible for the nonlinear response in the groundwater DO concentration.

\section{Results and Discussion}

\subsection{Observed Features in the Time Series of Groundwater DO Concentration}

[19] Time series plots (Figures 2-7) suggest that the groundwater DO concentrations in the aquifers analyzed are not statistically stationary, but undergo long-term trends and abrupt changes. In the next two sections, these two features in the historical data will be discussed in more detail.

\subsubsection{Long-Term Trends}

[20] Temporal trends in the DO data, calculated for the period 1979-2005 using the Theil-Sen method (Table 3), reveal a statistically significant $(p<0.05)$ long-term decrease in DO concentration at the $R h S e$ (Figure 4a), ToLi (Figures $6 \mathrm{a}$ and $7 \mathrm{a}-7 \mathrm{~d}$ ), and ToZe (Figure 7e) pumping wells. The ToLi data (Figures $6 \mathrm{a}$ and $7 \mathrm{a}-7 \mathrm{~d}$ ) suggest that this long-term decreasing trend encompassed the entire ToLi aquifer. The RhSe piezometer data (Figure 5), however, make it clear that the long-term behavior of the DO concentration within the $R h S e$ aquifer can be very heterogeneous. The DO concentration at EmSi (Figure 2b) underwent a long-term decrease from 1980 to 2000, but the trend for the period 1979-2005 was not significant because of a shift to higher DO concentrations after 2000. At AaKi (Figure $3 \mathrm{~b}$ ), DO concentrations showed the opposite behavior, with a rise having occurred in the long term (Table 3 ). The similar rates of decline in DO concentration observed at the EmSi, RhSe, ToLi, and ToZe pumping wells between approximately 1980 and 2000 (Figures 2b, 4a, 6a, and 7) suggest that a common external forcing factor governs the long-term behavior of the groundwater DO concentrations. However, the contradictory results for AaKi and the heterogeneity of the results from the RhSe piezometers show that local aquifer properties are also likely to play an important determining role.

\subsubsection{Abrupt Changes}

[21] DO concentrations measured at EmSi, AaKi, ToLi, and ToZe, and in RhSe piezometers G10, G11, and G101T, underwent abrupt, episodic increases and decreases at various points in time. At EmSi and $A a K i$, DO concentrations increased strongly from 2001 to 2002, and at ToLi and ToZe from 2008 to 2009 (Figures 2b, 3b, 6a, and 7; gray shaded areas). In $R h S e$ piezometers G10, G11, and G101T, a rapid, strong decrease in DO concentration from the early to the mid 1970s was followed by a multiannual period of low DO concentration and a subsequent rapid recovery phase in the late 1970s and early 1980s (Figures 5a-5c; gray shaded areas). The simultaneous occurrence of the abrupt changes at EmSi and AaKi suggests, as for the temporal trends, a common external forcing factor. However, the occurrence of abrupt changes at different points in time in the other aquifers shows that common external forcing is not the whole story.

\subsection{The Spatial Distribution of DO Concentration in the $R h S e$ and ToLi Aquifers}

[22] In order to analyze the spatial distribution of DO concentration at RhSe, the measuring sites (pumping well and piezometers) were divided into two groups based on their perpendicular distance from the riverbank, and the mean DO concentrations measured at the sites were compared using Student's $t$ test. The mean DO concentration measured at sites G10, G11, G101, and G101T, located close to the riverbank $(15-30 \mathrm{~m})$, was $6.0 \pm 2.2 \mathrm{mg} \mathrm{O}_{2} \mathrm{l}^{1}$, and that measured at sites PW, G19, G20, G21, G403, located much farther from the riverbank (520-2000 m), was $5.8 \pm 0.4 \mathrm{mg} \mathrm{O}_{2}{ }^{1}$. The difference between the two mean values $\left(0.2 \mathrm{mg} \mathrm{O}_{2} \mathrm{l}^{1}\right)$ was small and not statistically significant $(p=0.93)$. To exclude any effect of the excursion to low values in the 1970 s that was especially evident at G10 (Figure 5a), G11 (Figure 5b), and G101T (Figure 5c), the test was repeated using only the data from 1985 onward. Although the difference was greater $\left(1.3 \mathrm{mg} \mathrm{O}_{2}\right.$ $\left.1^{1}\right)$, it was still not statistically significant $(p=0.18)$. The data thus show that the mean DO concentration does not decrease substantially with increasing distance from the riverbank.

[23] Based on data from ToLi3 and ToLi4, Beyerle et al. [1999] came to a similar conclusion for the ToLi aquifer. They found oxygen consumption to be $2.8 \mathrm{mg} \mathrm{O}_{2} 1^{1}$ during passage through the hyporheic zone and $1.2 \mathrm{mg} \mathrm{O}_{2}$ $1^{1} \mathrm{yr}^{1}$ in the interior of the aquifer using DO concentration measurements and ${ }^{3} \mathrm{He}-{ }^{3} \mathrm{H}$ groundwater ages. Groundwater ages at ToLi3 and ToLi4 were estimated to be $10 \pm 3$ months and $13 \pm 3$ months, respectively [Beyerle et al., 1999].

[24] These findings indicate that, at least at RhSe and ToLi, oxygen consumption in the river-aquifer system occurs mainly or exclusively during infiltration; i.e., during passage through the hyporheic zone. Because of the similarity of the RBF systems analyzed in this study, we assume that this statement is also valid for aquifers $E m S i, A a K i$, and ToZe.

\subsection{Hypotheses Explaining the Observed Features}

[25] To explain the observed features of long-term trends and abrupt changes in the groundwater DO concentrations, we analyzed three hypotheses based on the available data:

[26] 1. Oxygen consumption rates in the hyporheic zone and within the aquifer were constant with time, and the long-term trends found in the groundwater DO 

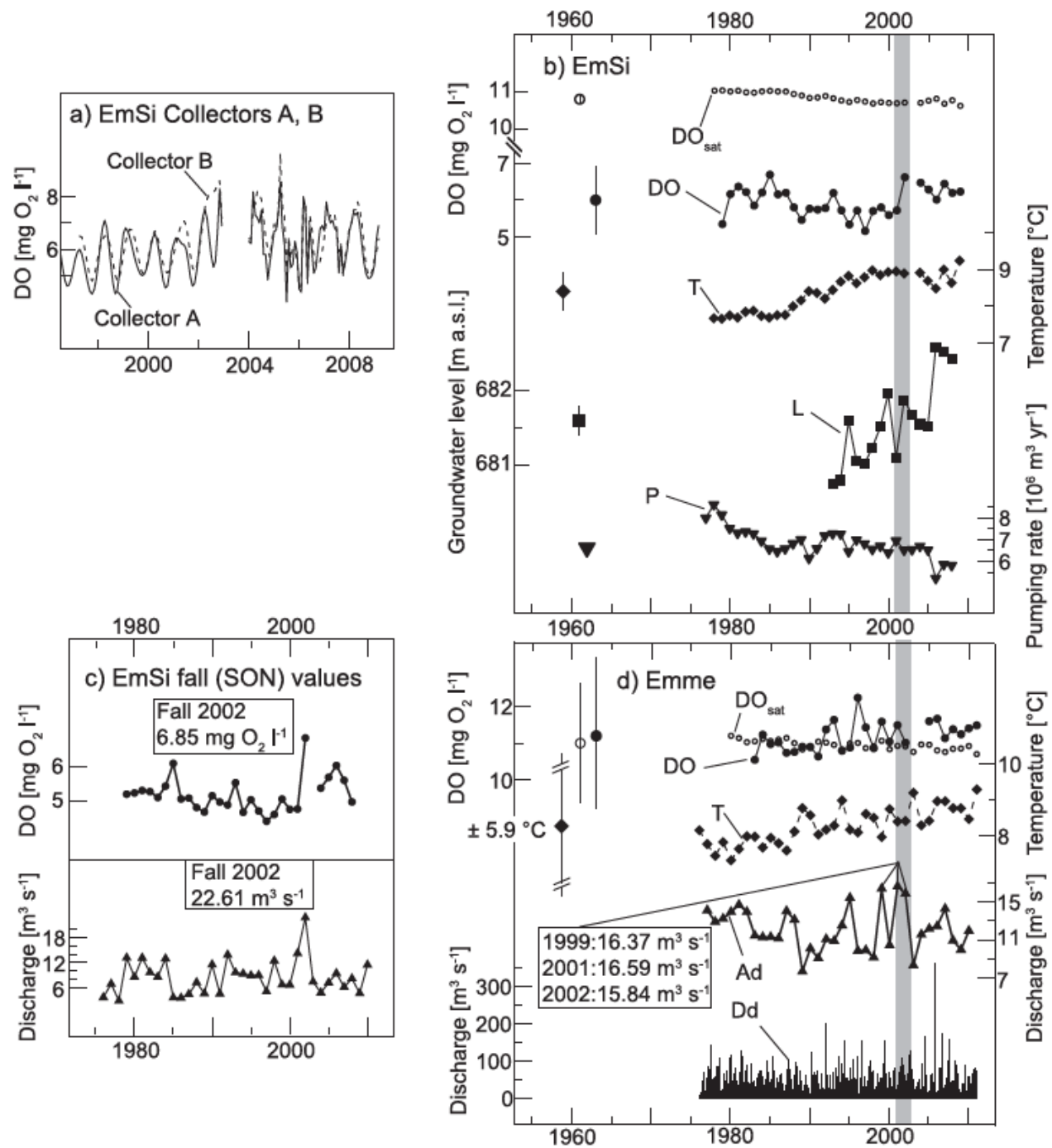

Figure 2. EmSi aquifer and River Emme. (a) Comparison of monthly mean DO concentrations in the EmSi aquifer as measured at Collectors A and B from 1997 to 2009. (b) Annual mean DO concentration (DO), groundwater temperature (T), DO saturation concentration ( $\mathrm{DO}_{\text {sat }}$ ), groundwater level (L), and annual pumping rate $(\mathrm{P})$ at Collector A of the EmSi aquifer. (c) Comparison of the mean fall (SeptemberNovember) DO concentration at the EmSi aquifer (top) with the mean fall discharge of the River Emme (bottom). (d) Annual mean DO concentration (DO), water temperature (T), DO saturation concentration $\left(\mathrm{DO}_{\text {sat }}\right.$ ), annual mean discharge (Ad), and daily mean discharge (Dd) for the River Emme. The symbols and vertical lines on the left-hand side of Figures $2 \mathrm{~b}$ and $2 \mathrm{~d}$ illustrate the mean value of each time series and its amplitude as determined from a trigonometric regression. The interrupted vertical line illustrating the amplitude of the River Emme water temperature (Figure 2d) was too large to fit on the plot, so the value is given explicitly. The shaded areas highlight the abrupt increase in groundwater DO concentration from 2001 to 2002 .

concentrations resulted from long-term trends in the DO concentration in the losing river.

[27] 2. An increase in groundwater temperature led both to a decrease in physical solubility and to an increase in microbial activity in the hyporheic zone, which in turn led to a decrease in groundwater DO concentration.

[28] 3. Changes in hydrological conditions-i.e., changes in pumping rate, river discharge rate, or groundwater level-affected the groundwater DO concentration by altering the residence time of the water in the microbiologically active hyporheic zone.

\subsubsection{The Influence of the DO Concentration in the} Losing River

[29] At ToLi and ToZe the decreases in DO concentration during the 1990s (Figures 6a and 7) appear to be associated with a simultaneous decrease in DO concentration in the River Toess (Figure 6b). However, no increase in DO concentration in the River Toess was observed from 2008 to 2009 that might explain the abrupt increase in groundwater DO concentration that occurred at both ToLi and ToZe at this time (Figures 6-7); in fact, the DO concentration in the River Toess decreased from 

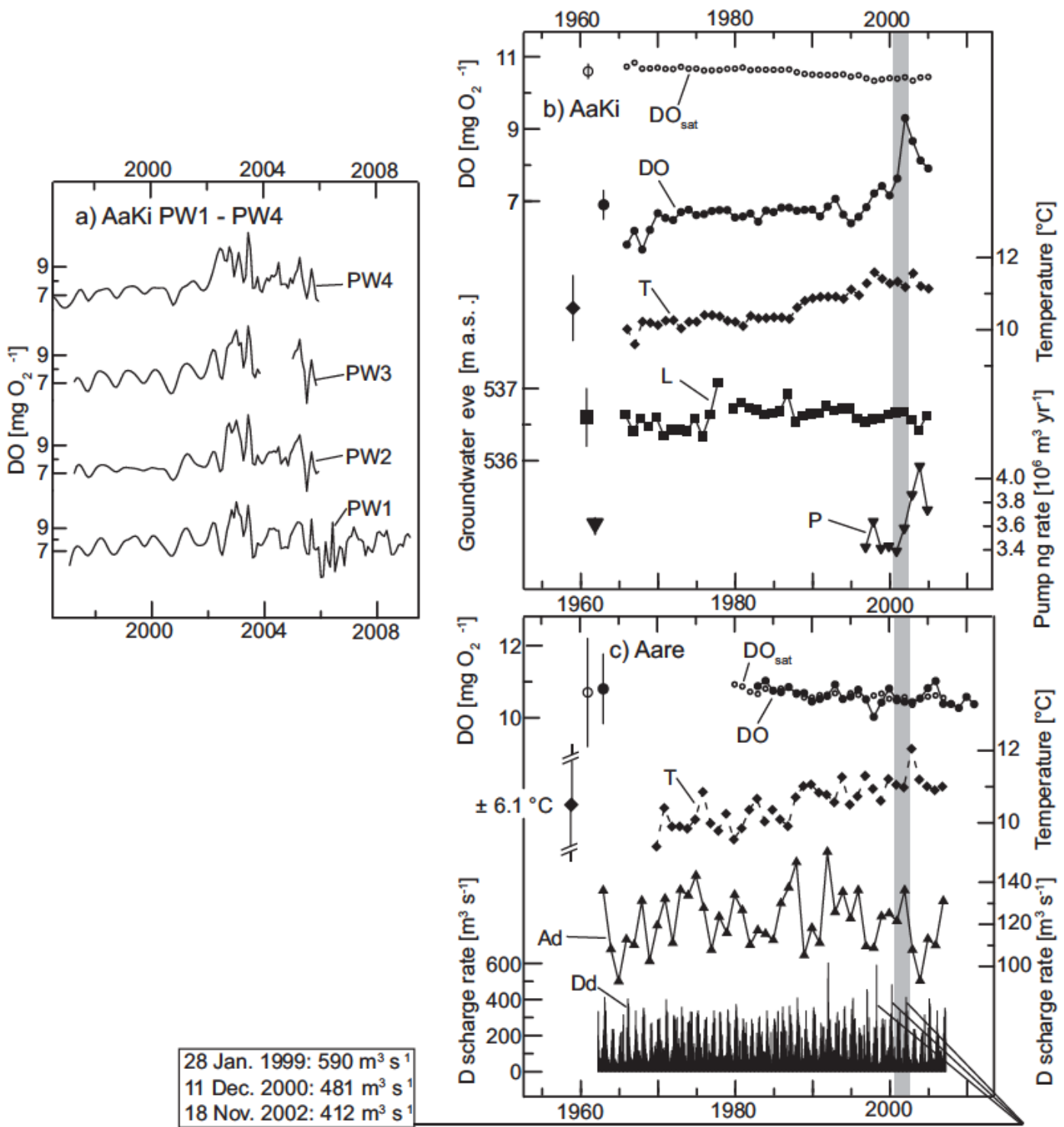

Figure 3. AaKi aquifer and River Aare. (a) Comparison of monthly mean DO concentrations measured at AaKi pumping wells PW1, PW2, PW3, and PW4 from 1997 to 2009. (b) Annual mean DO concentration (DO), groundwater temperature (T), DO saturation concentration ( $\mathrm{DO}_{\text {sat }}$ ), groundwater level (L), and annual pumping rate (P) measured in pumping well PW4 of the AaKi aquifer. (c) Annual mean DO concentration (DO), water temperature (T), DO saturation concentration ( $\mathrm{DO}_{\text {sat }}$ ), annual mean discharge (Ad), and daily mean discharge (Dd) for the River Aare. The symbols and vertical lines on the left-hand side of Figures $3 \mathrm{~b}$ and $3 \mathrm{c}$ illustrate the mean value of each time series and its amplitude as determined from a trigonometric regression. The interrupted vertical line illustrating the amplitude of the River Aare water temperature (Figure 3c) was too large to fit on the plot, so the value is given explicitly. The shaded areas highlight the abrupt increase in groundwater DO concentration from 2001 to 2002 .

2008 to 2009 (Figure 6b). At EmSi, AaKi, and RhSe, either no temporal trends in river-water DO concentration were found, or any trends that were found were opposite in sign to the trends found in groundwater DO concentration (Table 3 and Figures 2-5). Significant $(p<0.05)$ correlations between the annual mean groundwater DO concentrations in the RhSe, ToLi, and ToZe aquifers and the annual mean DO concentrations in the respective losing rivers (with lags of $0-2 \mathrm{yr}$ ) were mostly positive (Table 4). These correlations suggest that in the short term, groundwater DO concentrations might be influenced to some extent by the DO concentration in the losing river. Taking into account the large distances between the river gauging sites and the infiltration sites, however, the correlations between river-water and groundwater DO concentrations should be interpreted with caution. Nevertheless, the comparison of features such as trends and abrupt changes in the time series of DO concentration in the groundwater and in the losing river indicate that the long-term behavior of the DO concentration in groundwater is very unlikely to be governed primarily by the DO concentration in the losing river. 


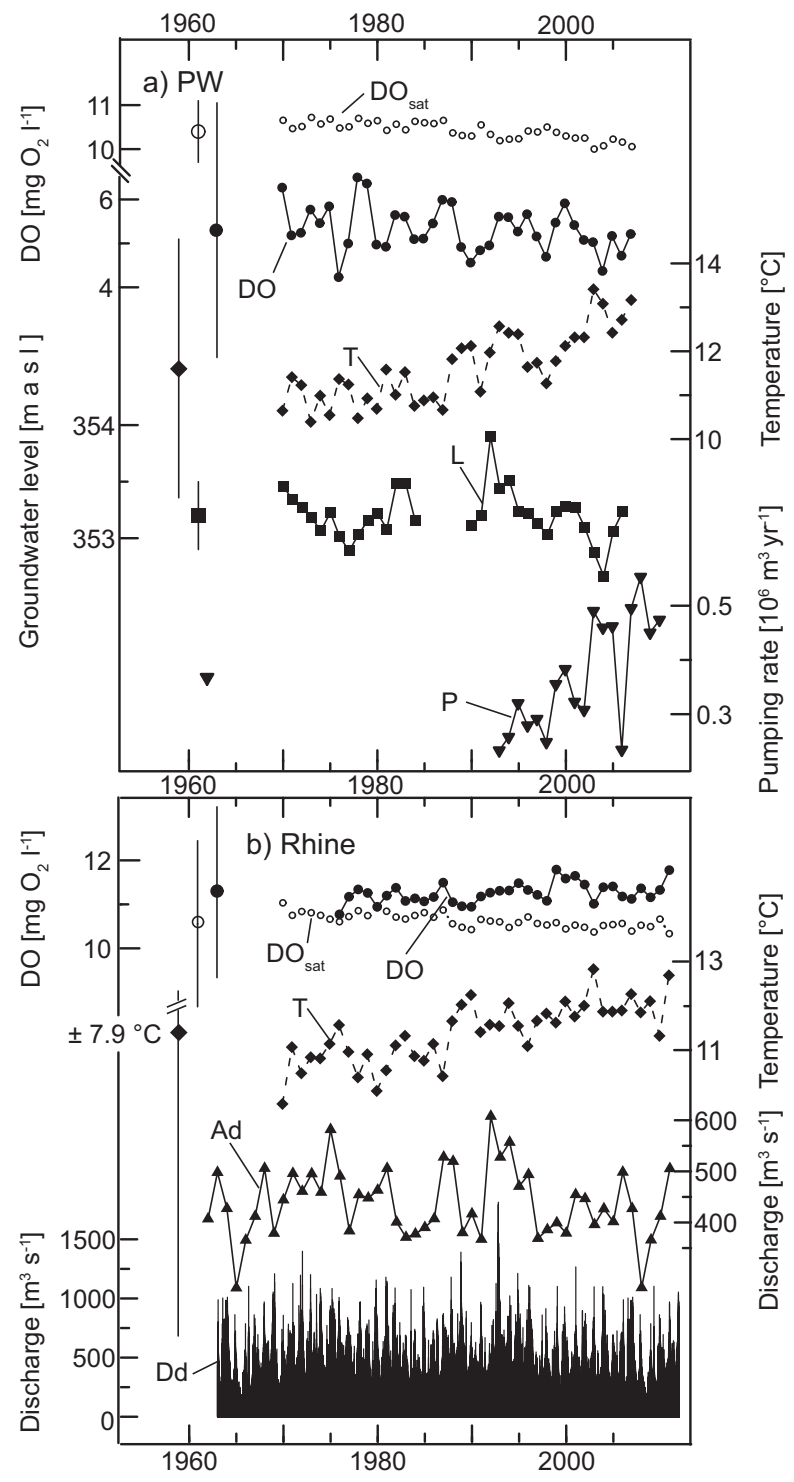

Figure 4. RhSe aquifer (PW) and River Rhine. (a) Annual mean DO concentration (DO), groundwater temperature $(\mathrm{T})$, DO saturation concentration $\left(\mathrm{DO}_{\mathrm{sat}}\right)$, groundwater level (L), and annual pumping rate $(\mathrm{P})$ measured in the pumping well of the RhSe aquifer. (b) Annual mean DO concentration (DO), water temperature $(\mathrm{T}), \mathrm{DO}$ saturation concentration $\left(\mathrm{DO}_{\mathrm{sat}}\right)$, annual mean discharge (Ad), and daily mean discharge (Dd) of the River Rhine. The symbols and vertical lines on the left-hand side of the panels illustrate the mean value of each time series and its amplitude as determined from a trigonometric regression. The interrupted vertical line illustrating the amplitude of the River Rhine water temperature (Figure 3b) was too large to fit on the plot, so the value is given explicitly.

\subsubsection{The Influence of Groundwater Temperature}

[30] At all sites where the DO concentration exhibits a decreasing trend (EmSi, RhSe, ToLi, and ToZe; Figures 2, 4-7 and Table 3), both groundwater temperature and riverwater temperature exhibit strong, increasing trends (Table 3 ). The trends in the computed groundwater DO saturation concentrations (Table 3) give an indication of how much the increase in groundwater temperature would reduce the physical solubility of oxygen. In the RhSe pumping well (Figure $4 a$ ) the similarity of the temporal trend in groundwater DO concentration to that of the DO saturation concentration suggests that the decrease in this pumping well might be attributable to the reduction in physical solubility resulting from the higher temperatures, with the contribution of microbial oxygen consumption (responsible for the difference between the DO saturation concentration and the measured DO concentration) being constant. In $R h S e$ piezometers G20 and G21, and in the pumping wells of the ToLi and ToZe aquifers, however, the decreasing trends in the DO concentration were greater than would be expected from trends in physical solubility alone (Table 3). This would imply that other effects-such as, presumably, enhanced microbial activity-were causing a further reduction in groundwater DO concentration. Further evidence supporting the temperature effect hypothesis is given by the significantly negative correlations $(p<0.05)$ between groundwater DO concentration and groundwater temperature at EmSi, RhSe (except piezometer G21), and ToLi (Table 4). Other results, on the other hand, suggest that this hypothesis might be too simplistic. For instance, at $A a K i$ the strong, long-term increase in groundwater temperature that began in the late 1980s [Figura et al., 2011] did not lead to a corresponding decrease in DO concentration. Further, the abrupt, strong increases in DO concentration observed at EmSi and AaKi from 2001 to 2002, and at ToLi and ToZe from 2008 to 2009, did not coincide with any significant drops in groundwater temperature.

[31] Despite the partially contradictory nature of the results, the hypothesis of a temperature-related decrease in groundwater DO cannot be rejected completely. Although the data do not unequivocally imply an increase in microbial activity, the strong warming observed in the aquifers [Table 3, Figura et al., 2011] suggests that groundwater temperature has likely contributed to the steady decrease in groundwater DO concentration. However, the presence of abrupt shifts in the groundwater DO concentration time series that are unrelated to groundwater temperature implies that temperature-dependent physical and microbial processes are not the only processes to have a strong impact on groundwater DO concentration.

\subsubsection{The Influence of Hydrological Variables}

[32] Temporal trends in river discharge rate and groundwater level are generally weak or absent (Table 3 ; no trends were calculated for pumping rate due to the scarcity of the data). Correlations between annual mean groundwater DO concentration and annual means of the pumping rate, river discharge rate, and groundwater level indicate no consistent relationship (Table 4). The results of trend and correlation analyses show that any influence that hydrological variables might have on the long-term evolution of the groundwater DO concentration is certainly not linear.

[33] An event-based comparison of groundwater DO concentration with pumping rate revealed a remarkably strong association between the two in the ToLi aquifer. The strong rise in DO concentration from 2008 to 2009 in the ToLi aquifer coincided with the unusually high pumping rates registered in 2009 (Figures 6a and 7a-7d), which were the result of a large-scale pumping test held in this 

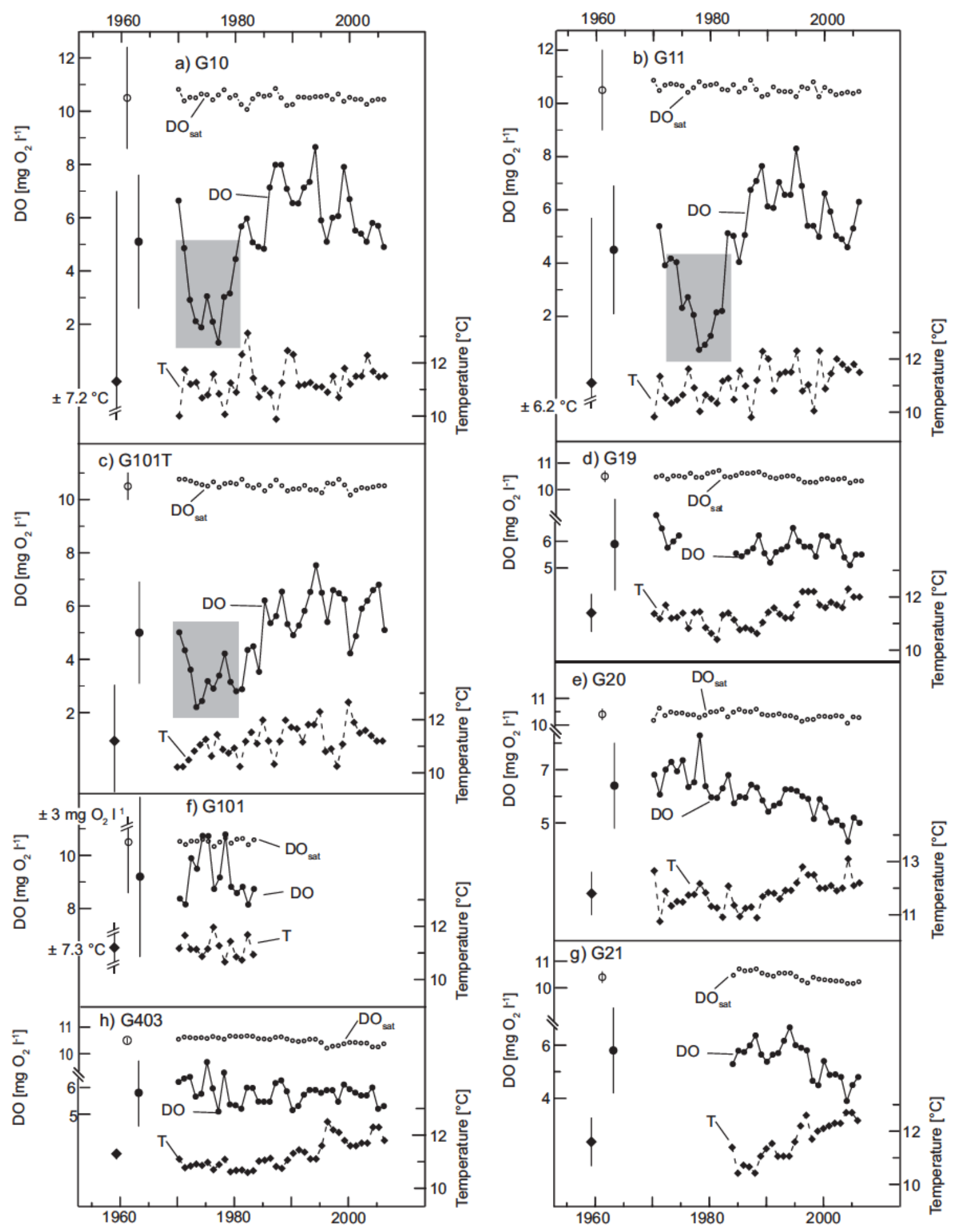

Figure 5. RhSe aquifer (piezometers). Annual mean DO concentrations (DO), groundwater temperatures $(\mathrm{T})$, and DO saturation concentrations $\left(\mathrm{DO}_{\text {sat }}\right)$ measured at the eight piezometers (G10, G11, G101, G101T, G19, G20, G21, and G403) of the RhSe aquifer. The symbols and vertical lines on the left-hand side of each panel illustrate the mean value of each time series and its amplitude as determined from a trigonometric regression. The interrupted vertical lines illustrating the amplitudes of the groundwater temperatures at G10, G11, G101, and of the DO saturation concentration at G101, were too large to fit on the plot, so their values are given explicitly (Figures 5a, 5b, and 5f). The shaded areas highlight the unusually low groundwater DO concentrations that occurred when the riverbed was clogged by zebra mussels (see text). 


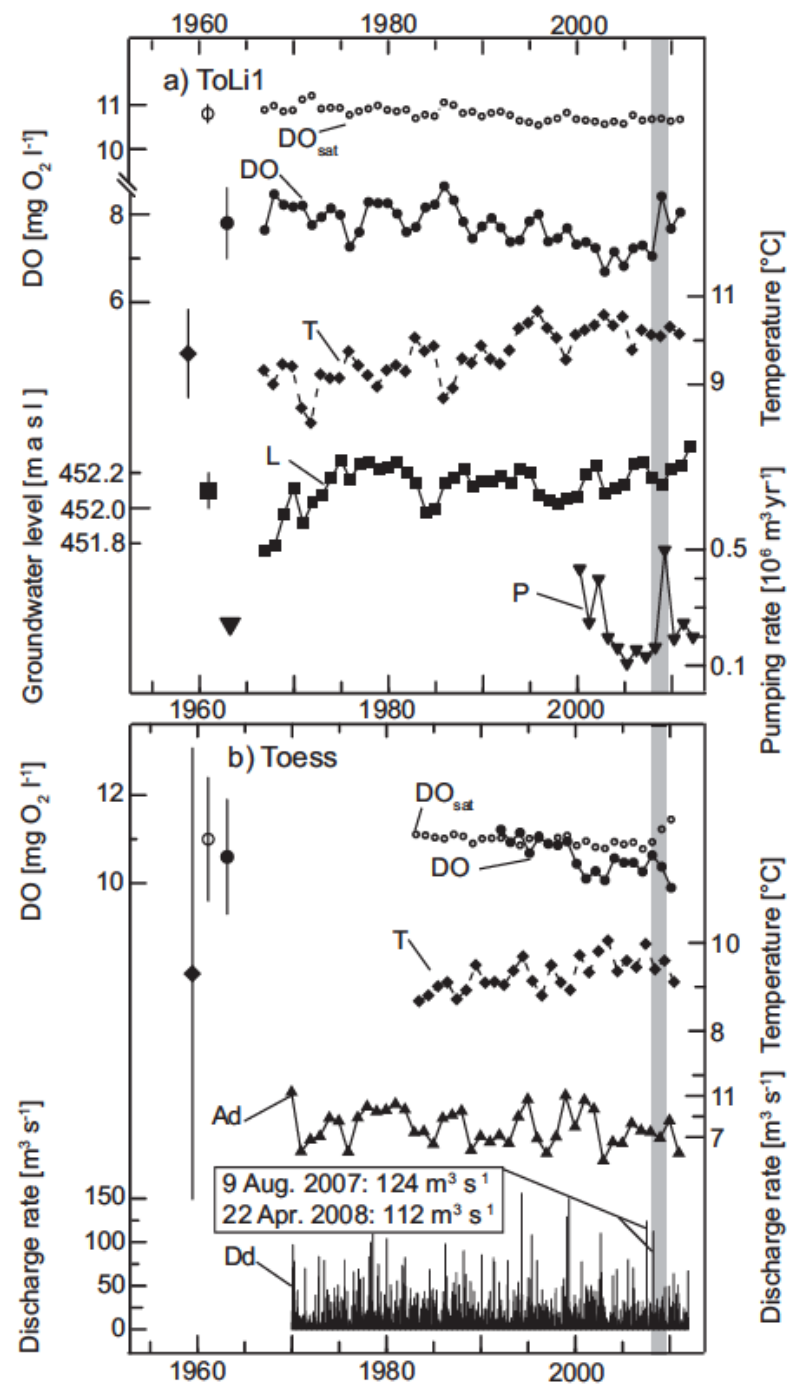

Figure 6. ToLi aquifer (ToLi1) and River Toess. (a) Annual mean DO concentration (DO), groundwater temperature $(\mathrm{T})$, DO saturation concentration $\left(\mathrm{DO}_{\text {sat }}\right)$, groundwater level (L), and annual pumping rate (P) measured in pumping well ToLil of the ToLi aquifer. (b) Annual mean DO concentration (DO), water temperature (T), DO saturation concentration ( $\left.\mathrm{DO}_{\text {sat }}\right)$, annual mean discharge (Ad), and daily mean discharge (Dd) of the River Toess. The symbols and vertical lines on the left-hand side of the panels illustrate the mean value of each time series and its amplitude as determined from a trigonometric regression. The shaded areas highlight the abrupt increase in groundwater DO concentration from 2008 to 2009.

year. These unusually high pumping rates in 2009 most probably led to the faster infiltration of a larger-than-usual volume of river water, resulting in a strong increase in DO concentration. At $A a K i$ also, the increase in DO concentration from 2001 to 2002 was accompanied by a slight increase in pumping rate (Figure $3 \mathrm{~b}$ ). However, high pumping rates were not always accompanied by sudden increases in DO concentration. Pumping rates even higher than those in 2009 were observed at ToLi3 in 2005 and at ToLi5 in 2003, but these had no effect on DO concentration (Figures 6a and $7 \mathrm{a}-7 \mathrm{~d})$; and at $A a K i$ pumping rates continued to increase after 2002, while groundwater DO concentration decreased (Figure 3b). Furthermore, at EmSi the rise in DO concentration from 2001 to 2002 was seemingly not caused by a change in pumping rate (Figure $2 \mathrm{~b}$ ), and in the $R h S e$ aquifer the pumping rate seems to have had no effect on groundwater DO concentration (Figure 4a).

[34] Abrupt increases in groundwater DO concentration that cannot be explained by high pumping rates can often be explained as the result of events of extremely high river discharge. At EmSi, AaKi, ToLi, and ToZe, sudden increases in groundwater DO concentration often coincided with, or immediately followed, such events. These findings are confirmed by the results of the intervention analysis (Table 5).

[35] At EmSi, the increase in groundwater DO concentration from 2001 to 2002 coincided with two years in which the annual mean discharge rate of the River Emme was unusually high (Figure 2d). The synchronicity of peak DO concentration and peak discharge rate was especially evident in the fall of 2002 (Figure 2c). Table 5 shows that an intervention model yielded the best fit with interventions in 1999, 2001, and 2002. The annual mean river discharge rates for these years were among the five highest values ever observed. The high river discharge rates in 1999, 2001, and 2002 (Figure 2d) presumably led to an increase in the infiltration of river water, evidenced by a strong rise in groundwater level from 2001 to 2002 (Figure 2b).

[36] At $A a K i$, a relatively high annual mean discharge in 2002 (Figure 3c) was observed, which, in combination with a slightly increased pumping rate (Figure $3 \mathrm{~b}$ ), might have led to the increase in DO concentration from 2001 to 2002. The relatively high annual mean discharge of the River Aare in 2002 (Figure 3c), though, did not affect groundwater DO concentration at $A a K i$ in the same way as at $\mathrm{EmSi}$, as there was no increase in groundwater level (Figure $3 \mathrm{~b}$ ) and the abrupt rise in DO concentration was not confined to fall, but was observed in all seasons. However, the abrupt increase in groundwater DO concentration was preceded by three individual major discharge events: on 28 January 1999, 11 December 2000, and 18 November 2002. We assume that in this case, repeated, intense scouring of the riverbed reduced clogging and facilitated the infiltration of river water, resulting in an increase in groundwater DO concentration. The intervention model fits best with a single intervention in 2002 (Table 5), highlighting the discharge event in 2002 as a potential cause of the increase in DO concentration from 2001 to 2002.

[37] As in the case of $A a K i$ in 2002, the sudden increases in DO concentration in the ToLi and ToZe pumping wells in 2009 (Figures 6a and 7) were preceded by major individual discharge events in 2007 (9 August) and 2008 (22 April) (Figure 6b). The intervention model yields the lowest RMSD values for interventions in 2007 and 2008 based on daily mean discharge data (Table 5). The previously mentioned absence of abrupt increases in DO concentration at $\mathrm{ToLi} 3$ in 2005 and ToLi5 in 2003, despite pumping rates that exceeded those in 2009 , is thus potentially a consequence of lower infiltration rates associated with a clogged riverbed. The scouring of the riverbed in 2007 and 2008 by the high-discharge events that occurred in these years would have allowed the infiltration rate, and hence the 

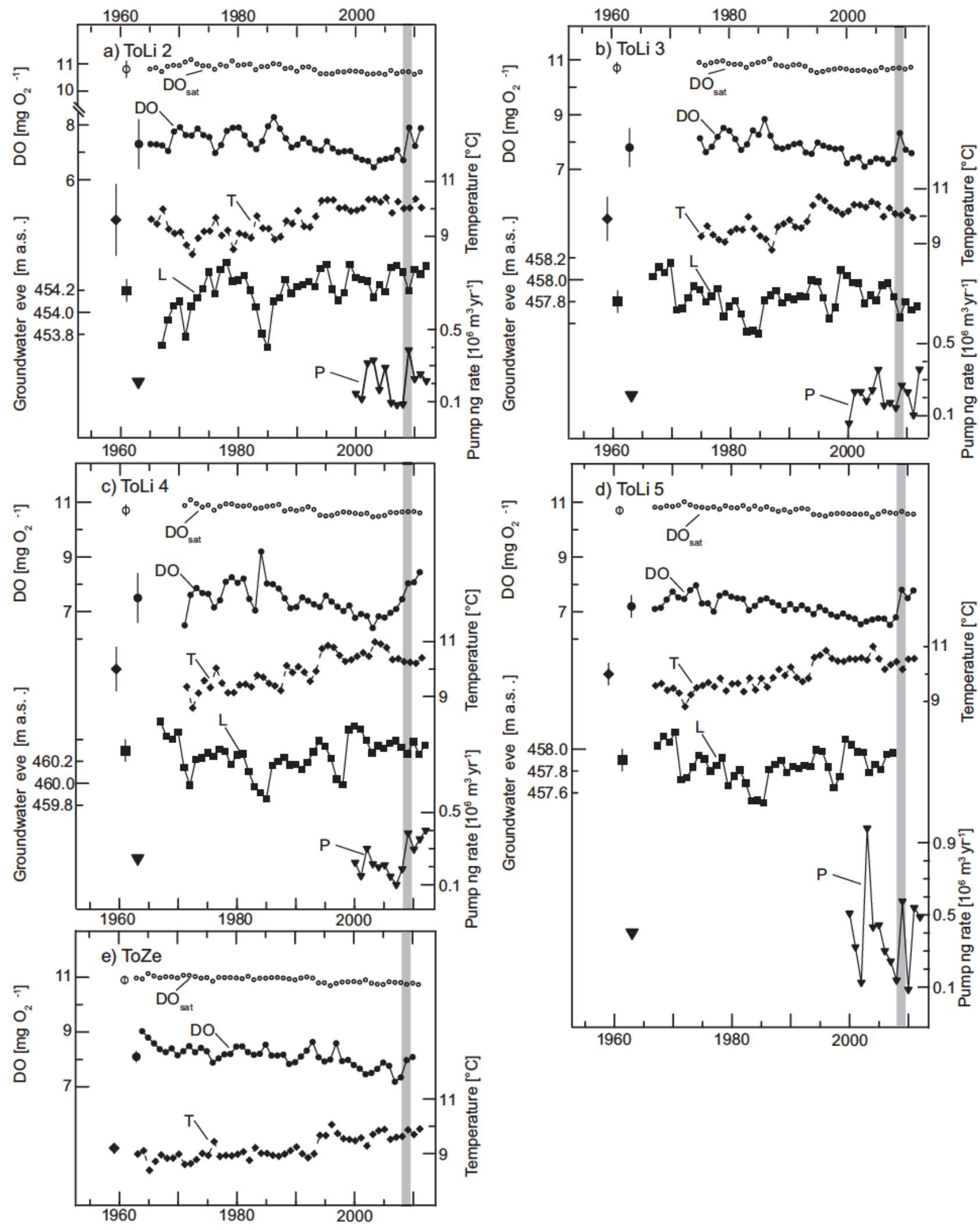

Figure 7. ToLi aquifer (ToLi2-ToLi5) and ToZe aquifer. (a-d) Annual mean DO concentration (DO), groundwater temperature $(\mathrm{T})$, DO saturation concentration $\left(\mathrm{DO}_{\text {sat }}\right)$, groundwater level $(\mathrm{L})$, and annual pumping rate $(\mathrm{P})$ measured in pumping wells ToLi2-ToLi5 of the ToLi aquifer. (e) Annual mean DO concentration (DO), groundwater temperature (T), and DO saturation concentration $\left(\mathrm{DO}_{\text {sat }}\right)$ measured in the ToZe aquifer. The symbols and vertical lines on the left-hand side of each panel illustrate the mean value of each time series and its amplitude as determined from a trigonometric regression. The shaded areas highlight the abrupt increase in groundwater DO concentration from 2008 to 2009 . 
Table 3. Temporal Trends ${ }^{\mathrm{a}}$

\begin{tabular}{|c|c|c|c|c|}
\hline \multicolumn{5}{|c|}{ (i) Groundwater } \\
\hline & $\mathrm{DO}\left(\mathrm{mg} \mathrm{O}_{2} 1^{1} \mathrm{yr}^{1}\right)$ & Temperature $\left({ }^{\circ} \mathrm{C}\right.$ yr $\left.{ }^{1}\right)$ & DO Saturation $\left(\mathrm{mg} \mathrm{O}_{2} 1^{1} \mathrm{yr}^{1}\right)$ & Groundwater Level $\left(\mathrm{cm} \mathrm{yr}^{1}\right)$ \\
\hline & 19792005 & 19792005 & 19792005 & 19792005 \\
\hline & (1992 2005) & (1992 2005) & (1992 2005) & (1992 2005) \\
\hline$\overline{E m S i}$ & ns (ns) & $0.060(0.036)$ & $0.016(0.010)$ & $(6.7)$ \\
\hline $\mathrm{AaKi}$ & 0.043 & 0.056 & 0.013 & 0.6 \\
\hline \multicolumn{5}{|l|}{ RhSe } \\
\hline PW & 0.016 & 0.071 & 0.017 & $\mathrm{~ns}$ \\
\hline G10 & ns & $\mathrm{ns}$ & $\mathrm{ns}$ & \\
\hline G11 & ns & 0.037 & 0.009 & \\
\hline \multicolumn{5}{|l|}{$\mathrm{G} 101^{\mathrm{b}}$} \\
\hline G101T & 0.082 & ns & ns & \\
\hline G19 & ns & 0.054 & 0.013 & \\
\hline G20 & 0.048 & 0.045 & 0.011 & \\
\hline G21 & 0.069 & 0.103 & 0.025 & \\
\hline G403 & ns & 0.055 & 0.015 & \\
\hline \multicolumn{5}{|l|}{ ToLi } \\
\hline ToLi1 & $0.045(0.053)$ & $0.052(0.051)$ & $0.013(0.013)$ & ns (ns) \\
\hline ToLi2 & $0.047(0.053)$ & $0.058(0.034)$ & $0.015(0.009)$ & ns (ns) \\
\hline ToLi3 & $0.041(0.052)$ & 0.049 (ns) & $0.013(\mathrm{~ns})$ & $1.0(1.3)$ \\
\hline ToLi4 & $0.057(0.056)$ & $0.062(0.061)$ & $0.016(0.016)$ & $1.0(\mathrm{~ns})$ \\
\hline ToLi5 & $0.037(0.042)$ & 0.051 (ns) & $0.013(\mathrm{~ns})$ & $1.0(1.2)$ \\
\hline ToZe & $0.028(0.064)$ & $0.036(\mathrm{~ns})$ & $0.009(\mathrm{~ns})$ & ( ) \\
\hline
\end{tabular}

(ii) River Water

\begin{tabular}{|c|c|c|c|c|}
\hline & $\mathrm{DO}\left(\mathrm{mg} \mathrm{O}_{2} 1^{1} \mathrm{yr}^{1}\right)$ & Temperature $\left({ }^{\circ} \mathrm{C}\right.$ yr $\left.{ }^{1}\right)$ & DO saturation $\left(\mathrm{mg} \mathrm{O}_{2} 1^{1} \mathrm{yr}^{1}\right)$ & Discharge rate $\left(\mathrm{m}^{3} \mathrm{~s}^{1}{ }^{1} \mathrm{yr}{ }^{1}\right)$ \\
\hline & 19792005 & 19792005 & 19792005 & 19792005 \\
\hline & (1992 2005) & (1992 2005) & (1992 2005) & (1992 2005) \\
\hline Emme & (ns) & $0.035(\mathrm{~ns})$ & 0.009 (ns) & ns (ns) \\
\hline Aare & 0.021 & 0.049 & 0.013 & ns \\
\hline Rhine & 0.014 & 0.054 & 0.013 & ns \\
\hline Toess & $(0.064)$ & $(0.042)$ & (ns) & ns (ns) \\
\hline
\end{tabular}

${ }^{\text {a }}$ Temporal trends (1979 2005) in the annual mean values of (i) groundwater DO concentration, groundwater temperature, groundwater DO saturation concentration, and groundwater level; and (ii) river-water DO concentration, river-water temperature, river-water DO saturation concentration, and river discharge rate as determined by the Theil-Sen method [Theil, 1950; Sen, 1968]. Tabulated values were tested for significance at the $p<0.05$ level using the nonparametric Kendall $\tau$ statistic [Helsel and Hirsch, 1992]. The lack of a significant trend (i.e., $p \geq 0.05$ ) is designated by "ns," and the lack of sufficient data by " ". Groundwater level at EmSi and DO concentrations in the rivers Emme and Toess were not available during the entire period 1979 2005 (Table 2). For comparison purposes, trends for EmSi and ToLi and for the rivers Emme and Toess were therefore also calculated for the period 19922005 (values in parentheses).

${ }^{\mathrm{b}}$ No DO concentration or temperature measurements were available for G101 after 1984.

groundwater DO concentration, to respond more sensitively to the increase in pumping rate from 2008 to 2009 . The abrupt increase in DO concentration from 2008 to 2009 was therefore a consequence of the interplay of two factors: riverbed scouring resulting from high-discharge events, and an increase in pumping rate.

[38] Evidence of the potential effect of riverbed clogging on groundwater DO concentration is given by observations made in the RhSe aquifer in the 1970s and 1980s. In the 1970 s, the operators of the RhSe pumping well discovered layers of zebra mussels (Dreissena polymorpha Pallas) up to $5 \mathrm{~cm}$ thick on the riverbed in the area between piezometers G10 and G101, where most of the infiltration of river water into the groundwater usually occurs, but diving expeditions showed that by the late 1980s this layer of zebra mussels had disappeared [Stahel, 1989]. Clogging of the riverbed by the zebra mussels presumably led to a reduction in the rate of infiltration of river water, so that $\mathrm{DO}$ concentrations in the piezometers close to the river (G10, G11, and G101T) dropped significantly over a period of several years (Figures 5a-5c). The disappearance of this layer of mussels allowed the river water to infiltrate faster, leading to an increase in DO concentration in the late 1970s and early 1980s (Figures 5a-5c).

[39] These results suggest that high pumping rates and high annual mean discharge rates lead to an increase in groundwater DO concentration by facilitating the infiltration of river water. Nevertheless, the examples of $A a K i$ and ToLi indicate that this process does not occur on every occasion when high pumping rates or high annual mean river discharge rates prevail. It seems that the intermittent scouring and unclogging of the riverbed by individual extreme river discharge events might be a necessary condition that must be fulfilled before pumping rates and annual mean river discharge rates can affect the infiltration of river water and, as a consequence, the groundwater DO concentration. Riverbed clogging, by extending the residence time of the infiltrating river water in the microbiologically active 
FIGURA ET AL.: COMPETING CONTROLS ON GROUNDWATER OXYGEN CONCENTRATIONS

Table 4. Correlations Between Annual Means of Groundwater DO Concentration and Potential Driving Variables ${ }^{\mathrm{a}}$

\begin{tabular}{|c|c|c|c|c|c|c|}
\hline & $\begin{array}{l}\text { River-Water DO } \\
\text { Concentration }\end{array}$ & $\begin{array}{l}\text { Groundwater } \\
\text { Temperature }\end{array}$ & $\begin{array}{c}\text { Groundwater DO } \\
\text { Saturation }\end{array}$ & Groundwater Level & River Discharge Rate & $\begin{array}{l}\text { Groundwater } \\
\text { Pumping Rate }\end{array}$ \\
\hline$E m S i$ & ns & $0^{* *}(\quad), 1^{*}(\quad)$ & $0^{* *}(+), 1^{*}(+)$ & ns & ns & ns \\
\hline $\begin{array}{l}\text { AaKi } \\
\text { RhSe }\end{array}$ & ns & ns & ns & ns & ns & ns \\
\hline PW & $0^{* * *}(+), 1^{* * *}(+)$ & $0^{*}()$ & $0^{*}(+)$ & ns & ns & ns \\
\hline G10 & $\mathrm{ns}$ & ns & $1^{*}(+)$ & & ns & \\
\hline G11 & ns & ns & ns & & ns & \\
\hline G101 & ns & $0^{*}(\quad)$ & ns & & ns & \\
\hline G101T & ns & $0^{* *}()$ & $0^{* *}(+)$ & & $\mathrm{ns}$ & \\
\hline G19 & $1^{*}(+)$ & ns & ns & & $0^{*}(+), 1^{*}(+), 2^{*}(+)$ & \\
\hline G20 & $0^{*}(+), 2^{*}(\quad)$ & ns & ns & & ns & \\
\hline G21 & ns & $0^{* *}()$ & $0^{* *}(+)$ & & $\mathrm{ns}$ & \\
\hline G403 & $0^{*}(+), 1^{*}(+)$ & $\mathrm{ns}$ & ns & & $0^{*}(+)$ & \\
\hline ToLi & & & & & & \\
\hline ToLi1 & $2^{*}(+)$ & $0^{*}()$ & ns & ns & ns & ns \\
\hline ToLi2 & $1^{* *}(+)$ & $0^{* *}(), 1^{*}()$ & $\mathrm{ns}$ & ns & ns & ns \\
\hline ToLi3 & $1^{*}(+)$ & $0^{* *}()$ & ns & ns & ns & ns \\
\hline ToLi4 & $1^{*}(+)$ & $0^{* * *}(\quad), 1^{*}()$ & ns & $2^{*}(+)$ & ns & ns \\
\hline ToLi5 & $1^{*}(+)$ & $0^{*}(), 1^{*}(), 2^{*}()$ & ns & ns & ns & $\mathrm{ns}$ \\
\hline ToZe & $\mathrm{ns}$ & $\mathrm{ns}$ & ns & & ns & \\
\hline
\end{tabular}

${ }^{\mathrm{a}} \mathrm{Lag}$ (from 0 to $2 \mathrm{yr}$ ) of the Spearman rank correlation coefficient between the time series of the annual mean groundwater DO concentration and the time series of the annual means of: DO concentration in the losing river; groundwater temperature; groundwater DO saturation concentration; groundwater level; discharge rate of the losing river; and groundwater pumping rate. The numbers listed are the lag in years (groundwater DO concentration lagging the potential driving variables) at which there is a positive $(+)$ or negative ( ) correlation significant at the $p<0.05$ level or better. Prior to calculating the correlations, all time series were detrended using the procedure of Cleveland et al. [1990]. Significance levels are: $p<0.05\left[{ }^{*}\right] ; p<0.01\left[^{* *}\right] ; p<0.001{ }^{[* * *}$ ]. The lack of any significant correlation at any lag from zero to $2 \mathrm{yr}(p>0.05)$ is denoted by "ns," and the lack of sufficient data by " ".

hyporheic zone, might also explain the periods of decreasing DO concentration at EmSi, RhSe, ToLi, and ToZe.

\section{Conclusions}

[40] The time series of groundwater DO concentration analyzed in this study all exhibited both long-term trends and abrupt changes. Of the three hypotheses considered as explanations for these two observed features, none could be excluded with certainty. The data indicate rather that these processes act as competing controls, which together determine the long-term behavior of the groundwater DO con- centration. We regard the following explanation of the observed long-term trends and abrupt increases in the groundwater DO time series as the most likely. During periods in which river-water infiltration is not affected substantially by alterations in the hydraulic regime (such as high pumping rates, extremes in river discharge, or changes in the state of the riverbed), increasing groundwater temperatures result in decreasing groundwater DO concentrations because of both a decrease in the physical solubility of oxygen, and an increase in microbial activity in the hyporheic zone and in the groundwater [Chapelle, 1993; Greig et al., 2007; Sprenger et al., 2011; Diem et al.,

Table 5. Results of the Intervention Analysis ${ }^{\mathrm{a}}$

\begin{tabular}{|c|c|c|c|c|c|c|c|c|}
\hline & EmSi & $A a K i$ & ToLi1 & ToLi2 & ToLi3 & ToLi4 & ToLi5 & ToZe \\
\hline $\begin{array}{l}\text { Order of ARIMA model for } N_{t} \\
\text { Annual mean discharge }\end{array}$ & $(1,0,0)$ & $(1,1,1)$ & $(1,0,2)$ & $(1,0,0)$ & $(1,0,0)$ & $(1,0,0)$ & $(1,0,0)$ & $(1,0,0)$ \\
\hline \multirow[t]{5}{*}{ Years of "extreme events" } & 2001 & 1992 & 1999 & 1999 & 1999 & 1999 & 1999 & 1999 \\
\hline & 1999 & 1988 & 1995 & 1995 & 1995 & 1995 & 1995 & 1995 \\
\hline & 2002 & 1987 & 2001 & 2001 & 2001 & 2001 & 2001 & 2001 \\
\hline & 1995 & 2002 & 1981 & 1981 & 1981 & 1981 & 1981 & 1981 \\
\hline & 2007 & 1996 & 2002 & 2002 & 2002 & 2002 & 2002 & 2002 \\
\hline RMSD & 0.16 & 0.21 & 0.24 & 0.30 & 0.35 & 0.59 & 0.22 & 0.23 \\
\hline \multicolumn{9}{|l|}{ Daily mean discharge } \\
\hline \multirow[t]{5}{*}{ Years of "extreme events" } & 2005 & 1992 & 1994 & 1994 & 1994 & 1994 & 1994 & 1994 \\
\hline & 2006 & 1999 & 1999 & 1999 & 1999 & 1999 & 1999 & 1999 \\
\hline & 2004 & 2001 & 1999 & 1999 & 1999 & 1999 & 1999 & 1999 \\
\hline & 2007 & 1997 & 2007 & 2007 & 2007 & 2007 & 2007 & 2007 \\
\hline & 1999 & 2002 & 2008 & 2008 & 2008 & 2008 & 2008 & 2008 \\
\hline RMSD & 0.29 & 0.21 & 0.20 & 0.28 & 0.30 & 0.47 & 0.18 & 0.20 \\
\hline
\end{tabular}

${ }^{a}$ Results of the intervention analysis model for groundwater DO concentration (equation (2)). The first term of equation $(2)\left(N_{t}\right)$ was modeled as an ARIMA model, the order of which is given in the first row. The second term of equation (2) $\left(m_{t}\right)$ is an exponential pulse function that represents the change in the mean caused by each intervention. Interventions were defined as having occurred in the five years containing the five highest values of annual mean discharge or daily mean discharge ("extreme events"). Allowing 15 interventions to take place, 31 combinations of years with an intervention are possible (see text). The years for which the inclusion of an intervention led to the best fit of the intervention model are highlighted in bold. The root mean square deviation (RMSD) shown is that between the measured DO concentration and the best-fit intervention model. The model was fitted using data from 1980 until the end of each DO time series. 
2013]. This may be compounded by a simultaneous decrease in DO concentration in the losing river. Increased clogging of the riverbed might also reduce the rate of infiltration of river water through the hyporheic zone [Schälchli, 1992; Nogaro et al., 2010], resulting in a more rapid decrease in groundwater DO concentration [Nogaro et al., 2010]. However, a combination of high pumping rates and high annual mean river discharge rates can result in sudden increases in groundwater DO concentration [Mauclaire and Gibert, 1998], but this is likely only after the occurrence of individual, extreme river discharge events that are severe enough to scour the riverbed and free it from clogging [Schälchli, 1992].

[41] Assuming air and river-water temperatures will continue to increase both globally [Kundzewicz et al., 2007; Meehl et al., 2007] and in Switzerland [CH2011, 2011; Federal Office for the Environment, 2012] during the current century, DO concentrations in the aquifers analyzed in this study are likely to exhibit a continued tendency to decrease gradually in the long term. This decreasing tendency will be countered by the effect of an increase in the frequency of high-discharge events in the losing rivers, which will probably result in intermittent scouring and unclogging of the riverbeds, followed by increased infiltration and abrupt increases in DO concentration. As a consequence, groundwater DO concentrations are unlikely to undergo an uninterrupted, steady decrease. Long-term hypoxia will therefore probably not occur in the type of aquifer analyzed in this study. Nevertheless, we assume that the risk of occurrence of extreme situations, such as documented by Hoehn and Scholtis [2011] for the summer of 2003, will increase. The risk of groundwater hypoxia will be higher if future hot, dry summers are preceded by several years with no discharge events intense enough to scour the riverbed sufficiently to reduce riverbed clogging.

[42] Acknowledgments. This research was funded by the Swiss National Science Foundation within the framework of National Research Program 61 on Sustainable Water Management. The authors are grateful to the "Climate and groundwater working group" of the Swiss Hydrogeological Society for its support in the search for relevant long-term groundwater data, and to the Swiss Federal Office of the Environment for partially funding the collection and digitization of the data used in this study.

\section{References}

Akaike, H. (1974), A new look at the statistical model identification, IEEE Trans. Autom. Control, 19(6), 716723.

Beyerle, U., W. Aeschbach-Hertig, M. Hofer, D. M. Imboden, H. Baur, and R. Kipfer (1999), Infiltration of river water to a shallow aquifer investigated with ${ }^{3} \mathrm{H} /{ }^{3} \mathrm{He}$, noble gases and CFCs, J. Hydrol., 220, 169185.

Blau, R. V., and F. Muchenberger (1997), Nutzungs-, Schutz- und Uberwachungskonzept fur die Grundwasserleiter des obersten Emmentals, zwischen Emmenmatt, Langnau und Eggiwil Synthesebericht, in Grundlagen fur Schutz und Bewirtschaftung der Grundwasser des Kantons Bern, Geotech. Inst. AG, Bern.

Boulton, A. J., S. Findlay, P. Marmonier, E. H. Stanley, and H. M. Valett (1998), The functional significance of the hyporheic zone in streams and rivers, Annu. Rev. Ecol. Syst., 29, 5981.

Bourg, C. M., and C. Bertin (1993), Biogeochemical processes during the infiltration of river water into an alluvial aquifer, Environ. Sci. Technol., 27, 661666.

Box, G. E. P., and G. Tiao (1975). Intervention analysis with applications to economic and environmental problems, J. Am. Stat. Assoc., 70, 7079.

Brunke, M., and T. Gonser (1997), The ecological significance of exchange processes between rivers and groundwater, Freshwater Biol., 37, 133.
Buhrer, H. (1975), Computerprogramm zur Bekanntgabe aktueller Seedaten, Schweiz. Z. Hydrol., 37, 332346.

Chapelle, F. H. (1993), Groundwater Microbiology and Geochemistry, John Wiley, New York.

CH2011 (2011), Swiss Climate Change Scenarios CH2011, 88 pp, C2SM, MeteoSwiss, ETH, NCCR Climate, and OcCC, Zurich, Switzerland.

Cleveland, R. B., W. S. Cleveland, J. E. McRae, and I. Terpening (1990), STL: A seasonal-trend decomposition procedure based on Loess, J. Off. Stat., 6, 373 .

Cryer, J. D., and K.-S. Chan (2008), Time series regression models, in Time Series Analysis: With Applications in R, edited by J. D. Cryer and K.-S. Chan, pp. 249 276, Springer, New York.

Diem, S., M. Rudolf von Rohr, J. G. Hering, H.-P. E. Kohler, M. Schirmer, U. von Gunten (2013), NOM degradation during river infiltration: Effects of the climate variables temperature and discharge, Water Res., doi:10.1016/j.watres.2013.08.028, in press.

Figura, S., D. M. Livingstone, E. Hoehn, and R. Kipfer (2011), Regime shift in groundwater temperature triggered by the Arctic Oscillation, Geophys. Res. Lett., 38, L23401, doi : 10.1029/2011GL049749.

Federal Office for the Environment (2012), Effects of climate change on water resources and watercourses. Synthesis report on the "Climate Change and Hydrology in Switzerland (CCHydro)" project, in UmweltWissen Nr. 1217, 76 pp, Fed. Off. for the Environ., Bern.

Federal Office of Public Health (2003), Schweizerisches Lebensmittelbuch, Kapitel 27A Trinkwasser, Federal Off. of Public Health, Bern.

Green, T. R., M. Taniguchi, H. Kooi, J. J. Gurdak, D. M. Allen, K. M. Hiscock, H. Treidel, and A. Aureli (2011), Beneath the surface of global change: Impacts of climate change on groundwater, J. Hydrol., $405(3$ 4), 532560 .

Greig, S. M., D. A. Sear, and P. A. Carling (2007), A review of factors influencing the availability of dissolved oxygen to incubating salmonid embryos, Hydrol. Processes, 21, 323334.

Hari, R. E., D. M. Livingstone, R. Siber, P. Burkhardt-Holm, and H. Guttinger (2006), Consequences of climatic change for water temperature and brown trout populations in Alpine rivers and streams, Global Change Biol., 12(1), 1026.

Helsel, D. R., and R. M. Hirsch (1992), Statistical Methods in Water Resources, Elsevier, Amsterdam.

Hoehn, E., and A. Scholtis (2011), Exchange between a river and groundwater, assessed with hydrochemical data, Hydrol. Earth Syst. Sci., 15, 983988.

Hunt, H., J. Schubert, and C. Ray (2002), Operation and maintenance considerations, in Riverbank Filtration: Improving Source-Water Quality, Water Science and Technology Library, vol. 43, edited by C. Ray et al., pp. 61 70, Kluwer Acad., Dordrecht, Netherlands.

Kellerhals, P., C. Haefeli, and B. Tröhler (1981), Hydrogeologie Aaretal, zwischen Thun und Bern, in Grundlagen fur Schutz und Bewirtschaftung der Grundwasser des Kantons Bern, edited by P. Kellerhals et al. Wasser- und Energiewirtschaftsamt des Kantons Bern, Bern, Switzerland.

Kempf, T., M. Freimoser, P. Haldimann, V. Longo, E. Muller, C. Schindler, G. Styger, and L. Wyssling (1986), Die Grundwasservorkommen im Kanton Zurich, in Beitrage zur Geologie der Schweiz, Geotech. Ser., vol. 69, edited by T. Kempf, Kummerly and Frey, Bern, Switzerland.

Kundzewicz, Z. W., L. J. Mata, N. W. Arnell, P. Döll, P. Kabat, B. Jiménez, K. A. Miller, T. Oki, Z. Sen, and I. A. Shiklomanov (2007), Freshwater resources and their management, in Climate Change 2007: Impacts, Adaptation and Vulnerability. Contribution of Working Group II to the Fourth Assessment Report of the Intergovernmental Panel on Climate Change, edited by M. L. Parry et al., pp. 173 210, Cambridge Univ. Press, Cambridge, U. K.

Malard, F., and F. Hervant (1999), Oxygen supply and the adaptations of animals in groundwater, Freshwater Biol., 41, 130.

Mattle, N., W. Kinzelbach, U. Beyerle, P. Huggenberger, and H. H. Loosli (2001), Exploring an aquifer system by integrating hydraulic, hydrogeologic and environmental tracer data in a three-dimensional hydrodynamic transport model, J. Hydrol., 242, 183196.

Mauclaire, L., and J. Gibert (1998), Effects of pumping and floods on groundwater quality: A case study of the Grand Gravier well field (Rhône, France), Hydrobiologia, 389, 141151.

Meehl, G. A., et al. (2007), Global climate projections, in Climate Change 2007: The Physical Science Basis. Contribution of Working Group I to the Fourth Assessment Report of the Intergovernmental Panel on Climate Change, edited by S. Solomon et al., pp. 748 846, Cambridge Univ. Press, Cambridge, U. K. 


\section{FIGURA ET AL.: COMPETING CONTROLS ON GROUNDWATER OXYGEN CONCENTRATIONS}

Nogaro, G., T. Datry, F. Mermillod-Blondin, S. Descloux, and B. Montuelle (2010), Influence of streambed sediment clogging on microbial processes in the hyporheic zone, Freshwater Biol., 55, 12881302.

Ray, C., J. Schubert, R. B. Linsky, and G. Melin (2002), Introduction, in Riverbank Filtration: Improving Source-Water Quality, Water Science and Technology Library, vol. 43, edited by C. Ray et al., pp. 1 18, Kluwer Acad., Dordrecht, Netherlands.

R Development Core Team (2011), R: A Language and Environment for Statistical Computing, R Found. for Stat. Comput., Vienna.

Rohns, H.-P., C. Forner, P. Eckert, and R. Irmscher (2006), Efficiency of riverbank filtration considering the removal of pathogenic microorganisms of the River Rhine, in Recent Progress in Slow Sand and Alternative Biofiltration Processes, edited by R. Gimbel et al., pp. 539 546, IWA Publ., London.

Schalchli, U. (1992), The clogging of coarse gravel river beds by fine sediment, Hydrobiologia, 235/236, 189197.

Schar, C., P. L. Vidale, D. Luthi, C. Frei, C. Haberli, M. A. Liniger, and C. Appenzeller (2004), The role of increasing temperature variability in European summer heatwaves, Nature, 427, 332336.
Sen, P. K. (1968), Estimates of the regression coefficient based on Kendall's $\tau$, J. Am. Stat. Assoc., 63, 13791389.

Sprenger, C., G. Lorenzen, J. Hulshoff, G. Grutzmacher, M. Ronghang, and A. Pekdeger (2011), Vulnerability of bank filtration systems to climate change, Sci. Tot. Environ., 409(4), 655663.

Stahel, W. (1989), Rheinsohleuntersuchungen im Kraftwerkstau Rheinau, in Kraftwerk Rheinau, Grundwasserverhaltnisse. Bericht der Grundwasserkommission uber die Untersuchungen im Zusammenhang mit der Erstellung des Kraftwerks, edited by P. Giger et al. (1990), Grundwasserkommission Kraftwerk Rheinau technical report Nr. 2, Zurich, Switzerland.

Theil, H. (1950), A rank-invariant method of linear and polynomial regression analysis I-III, Nederl. Akad. Wetensch. Proc., 53, 3861412.

von Gunten, H. R., G. Karametaxas, U. Krahenbuhl, M. Kuslys, R. Giovanoli, E. Hoehn, and R. Keil (1991), Seasonal biogeochemical cycles in riverborne groundwater, Geochem. Cosmochem. Acta, 55(12), 3597 3609 . 